\title{
Local population structure of a naturally occurring metapopulation of the quokka (Setonix brachyurus Macropodidae: Marsupialia)
}

\author{
Matt W. Hayward ${ }^{\mathrm{a}, \mathrm{b}, \mathrm{c}, *}$, Paul J. de Tores ${ }^{\mathrm{b}, \mathrm{c}}$, Michael J. Dillon ${ }^{\mathrm{c}}$, Barry J. Fox ${ }^{\mathrm{a}}$ \\ ${ }^{a}$ School of Biological, Earth and Environmental Science, University of New South Wales, Sydney, NSW 2052, Australia \\ ${ }^{\mathrm{b}}$ Department of Conservation and Land Management, Wildlife Research Centre, PO Box 51 Wanneroo, WA 6946, Australia \\ ${ }^{\mathrm{c}}$ Department of Conservation and Land Management, Dwellingup Research Centre, Banksiadale Road, Dwellingup, WA 6213, Australia
}

Received 8 May 2002; received in revised form 18 July 2002; accepted 22 July 2002

\begin{abstract}
We investigated the population structure of the quokka (Setonix brachyurus) on the mainland of Western Australia using markrecapture techniques. Seven previously known local populations and one unconfirmed site supporting the preferred, patchy and discrete, swampy habitat of the quokka were trapped. The quokka is now considered as locally extinct at three sites. The five remaining sites had extremely low numbers, ranging from 1 to 36 individuals. Population density at these sites ranged from 0.07 to 4.3 individuals per hectare. There has been no response to the on-going, 6 year fox control programme occurring in the region despite the quokkas' high fecundity and this is due to low recruitment levels. The remaining quokka populations in the northern jarrah forest appear to be the terminal remnants of a collapsing metapopulation.
\end{abstract}

(C) 2002 Elsevier Science Ltd. All rights reserved.

Keywords: Population structure; Predation; Reproduction; Setonix brachyurus; Vulnerable

\section{Introduction}

The quokka (Setonix brachyurus Quoy \& Gaimard 1830), is a small, macropodid marsupial that is endemic to the south west of Australia (Kitchener, 1995). It is the sole member of its genus and its affinities within the subfamily Macropodinae are extremely uncertain (Baverstock et al., 1989; Kirsch et al., 1995; Burk et al., 1998).

The quokka was widespread and abundant when Europeans settled the south west in the 1830 s where it was distributed along the coast and high rainfall forested areas as well as on Rottnest, Bald and Breaksea Islands (Shortridge, 1909; Gould, 1973; Kitchener and Vicker, 1981; Kitchener, 1995). On the mainland the species suffered a drastic decline in abundance and distribution during the 1930s (White, 1952) which corresponded to the arrival of the red fox (Vulpes vulpes; King and Smith, 1985). Today the quokka is listed as vulnerable according to IUCN criteria (Hilton-Taylor, 2000).

\footnotetext{
* Corresponding author. Fax: +612-9385-1558.

E-mail address: hayers111@aol.com (M.W. Hayward).
}

The Rottnest Island quokka population fluctuates around 5000 with peaks of 10,000 individuals (Waring, 1956). The Bald Island population ranges from 200 to 600 (Main and Yadav, 1971). Estimates indicate populations at the northern extent of the species' mainland range rarely exceed 10 adults (Sinclair and Morris, 1996). These remnant local populations are restricted to discrete and scattered, swampy habitat patches which are dominated by the tall shrub Agonis linearifolia (White, 1952; Christensen and Kimber, 1975).

Quokkas have been extensively studied on Rottnest Island; however environmental and ecological differences between the island and mainland suggest ecological attributes cannot be extrapolated between the two (White, 1952; Dunnet, 1962; Shield, 1964; Storr, 1964; Kitchener, 1972; Mead et al., 1985). Despite the longterm knowledge of the decline of the quokka on the mainland (White, 1952) and therefore the apparent need to investigate the causes, important ecological research has not proceeded. Research has been hampered by the difficulty in locating and capturing animals (Sinclair and Morris, 1996) and by a lack of available resources. Consequently, this study aimed to derive more reliable estimates of population size at known localities within 
the northern jarrah forest; and to collect data on the demography, morphology and reproduction of each population.

\section{Study area}

\subsection{Vegetation and climate}

The jarrah forest of Western Australia is a tall, open forest dominated by Eucalyptus marginata (jarrah) and Corymbia calophylla (marri). Agonis swamp shrublands occur on alluvial deposits along the upper reaches of creek systems in its western half (Heddle et al., 1980). Forest populations of the quokka are restricted to these densely vegetated swamps (Barker et al., 1957; Storr, 1964; Christensen, et al., 1985).

The northern jarrah forest is within the Darling subdistrict (Beard, 1980) of the Jarrah Forest biogeographic region (Thackway and Cresswell, 1995). It extends from Mundaring in the north to Collie in the south and is bounded to the west by the Darling Range and the east by the cleared agricultural areas of the wheatbelt (Fig. 1; Beard, 1980). The study area has a Mediterranean climate characterised by hot, dry summers and mild, wet winters (Southern, 1979). The general region abuts the two largest cities in Western Australia (Perth and Bunbury; Fig. 1) which suggests a high potential for disturbance and environmental degradation. The area was selected for this study as it is at the northern limit of extant quokka distribution and threats throughout its range are likely to have had a greater impact there.

\section{Study sites}

Ten sites were initially investigated for quokka presence (Fig. 1). Sites were classed as swamp, or the upper reaches of creek systems vegetated by Agonis linearifolia, and the surrounding jarrah forest. Nine of these sites supported quokkas in the early 1990s and there was an unconfirmed quokka sighting at the Hoffman site in the late 1990s (A. Danks personal communication). The Albany Highway and Gervasse sites were eventually excluded from the project due to feasibility constraints arising from the additional costs incurred for travel and the additional time required to trap these sites that are at the extremities of the study region (Fig. 1).

\subsection{Fox baiting}

Having evolved in association with the poison-bearing plants of the genus Gastrolobium, many Western Australian native fauna species, including the quokka, have a relatively high tolerance to the toxin sodium mono- fluoroacetate (1080), particularly when compared with introduced species (King et al., 1981; Mead et al., 1985). The local area around the Rosella Road, Chandler Road, Wild Pig Swamp, Kesners, Hadfield, Albany Highway and Gervasse sites is baited monthly with dried meat injected with $4.5 \mathrm{mg}$ of 1080 . Baits are delivered from vehicles at intervals of $100 \mathrm{~m}$. The area surrounding these sites is also subject to broad-scale, aerial fox poisoning at five baits $\mathrm{km}^{-2}$ as part of the Department of Conservation and Land Management's fox control programmes (de Tores, 1994, 1999; Thomson and Algar, 2000). Preliminary results indicate that sites with an increased frequency of baiting show significantly higher levels of survivorship of predationsensitive species (de Tores, 1999) suggesting a decrease in fox density. The remaining three sites were unbaited. Two of these, the Holyoake and Hoffman sites, were trapped in an attempt to confirm quokka presence and to establish another unbaited control population in addition to Victor Road. The location, length and fox control details of the eight sites trapped are shown in Table 1.

\section{Methods}

\subsection{Trapping}

Trapping was conducted by MWH at eight sites (Fig. 1) where the entire Agonis-dominated areas of the creek lines were trapped. Trap stations were situated every $50-100 \mathrm{~m}$ along the creek line. At each trap station, one large and one small wire cage trap were placed inside the swamp while a corresponding pair was placed between 30 and $80 \mathrm{~m}$ outside the swamp.

The two sizes of trap were used to reduce non-target captures in the large traps and to minimise unequal catchability of individual quokkas. The large wire cage traps measured $0.90 \times 0.45 \times 0.45 \mathrm{~m}$ while the small wire cage traps measured $0.59 \times 0.205 \times 0.205 \mathrm{~m}$. Large traps were baited with apples while the small traps were baited with a 'universal' mix of peanut butter, rolled oats, honey and pilchards. A free-feeding, pre-baiting period of 6 or 7 days was used, after which traps were opened and cleared each morning for 8 days.

Open population estimates are thought to require a minimum of three primary trapping periods (e.g. years/ seasons/months/weeks) each containing five secondary sampling periods (e.g. days/hours) depending on the target species (Pollock, 1982). Anecdotal information and previous quokka trapping experience indicated that the northern jarrah forest quokka sites were at low population density and that quokkas exhibit trap shyness and therefore have low capture probabilities. Consequently, a trapping regime of at least seven primary (seasonal) and eight secondary (days) trapping periods was implemented to provide a more robust data set. 


\subsection{Animal handling and measurements}

Captured animals were removed from traps and placed in hessian bags. Quokkas were sedated via intramuscular injections with nominal doses of ketamine $\left(9 \mathrm{mg} \mathrm{kg}^{-1}\right)$ and xylazil (2.5 $\mathrm{mg} \mathrm{kg}^{-1}$ ) which provided 30-60 minutes of sedation. Each animal was weighed and pes length and tail circumference - an indicator of condition (Bakker and Main, 1980)—were measured. Reproductive status was assessed via testes and pouch inspections.

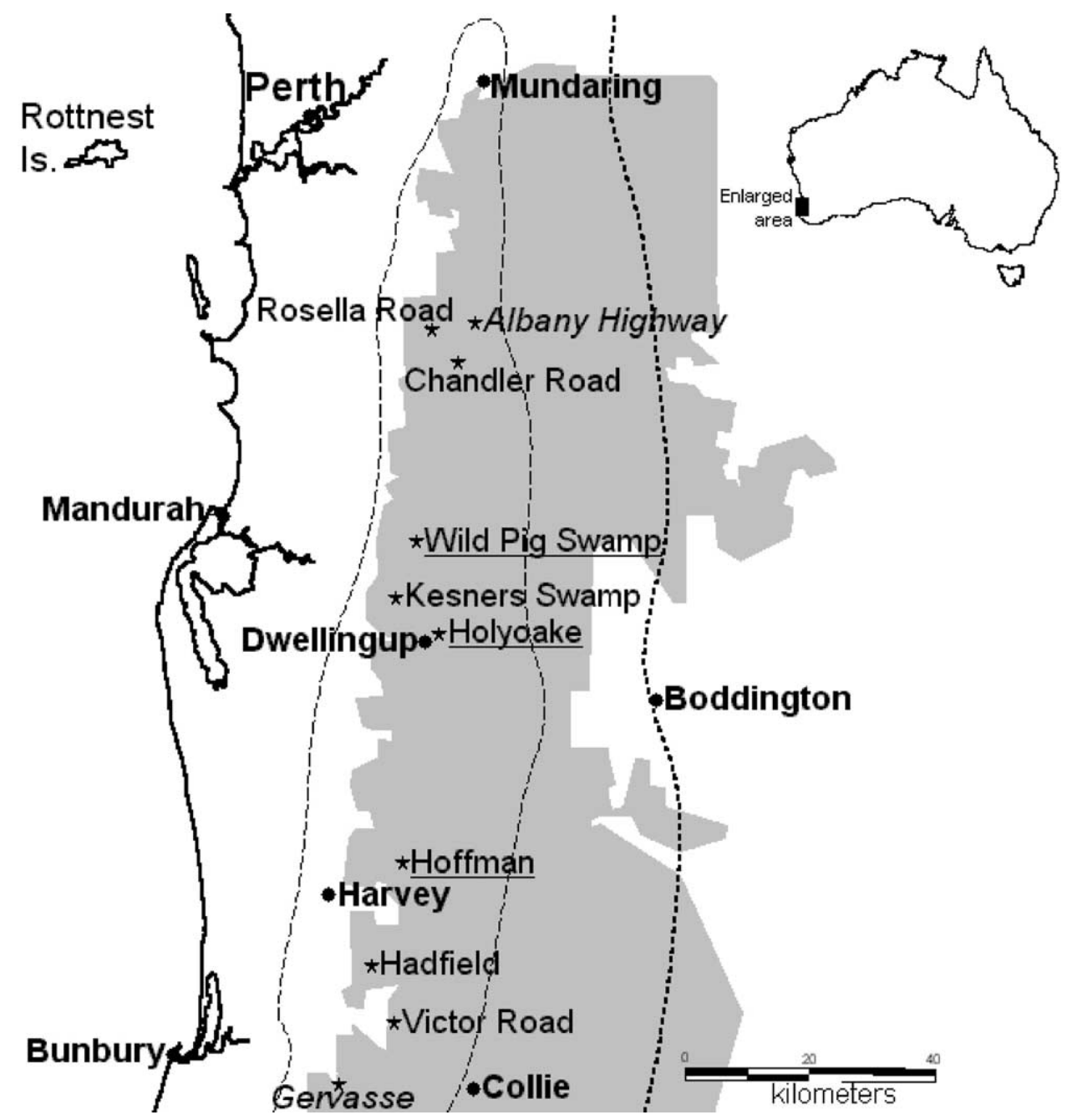

Fig. 1. Location map of the study region. Study sites are shown with stars. Sites underlined were trapped but contained no quokkas while sites shown in italics were excluded due to feasibility constraints. Towns are shown in bold and are depicted by filled circles. The northern jarrah forest is shaded grey and the Darling Range generally runs along its western boundary. The $1000 \mathrm{~mm}$ (dashed line) and $700 \mathrm{~mm}$ (dotted line) annual rainfall isohyets are also shown.

Table 1

Details of the location, size and baiting history of quokka swamps investigated during this study

\begin{tabular}{|c|c|c|c|c|c|}
\hline Site & Latitude (S) & Longitude (E) & Length (m) & Area (ha) & Monthly fox control start \\
\hline Chandler Road & $32^{\circ} 18^{\prime} 24^{\prime \prime}$ & $116^{\circ} 07^{\prime} 20^{\prime \prime}$ & 1340 & 11.3 & March 1998a \\
\hline Hadfield & $33^{\circ} 11^{\prime} 07^{\prime \prime}$ & $115^{\circ} 58^{\prime} 25^{\prime \prime}$ & 1570 & 6.8 & October $1997^{\mathrm{b}}$ \\
\hline Kesners & $32^{\circ} 39^{\prime} 00^{\prime \prime}$ & $116^{\circ} 00^{\prime} 59^{\prime \prime}$ & 2510 & 12.4 & January $1999^{b}$ \\
\hline Rosella Road & $32^{\circ} 15^{\prime} 34^{\prime \prime}$ & $116^{\circ} 04^{\prime} 36^{\prime \prime}$ & 1690 & 15.3 & March 1998a \\
\hline Wild Pig & $32^{\circ} 34^{\prime} 07^{\prime \prime}$ & $116^{\circ} 03^{\prime} 03^{\prime \prime}$ & 1200 & 9.9 & March $1999^{\mathrm{b}}$ \\
\hline Hoffman & $33^{\circ} 02^{\prime} 12^{\prime \prime}$ & $116^{\circ} 01^{\prime} 34^{\prime \prime}$ & 2000 & 8.0 & Unbaited \\
\hline Holyoake & $32^{\circ} 42^{\prime} 14^{\prime \prime}$ & $116^{\circ} 05^{\prime} 24^{\prime \prime}$ & 500 & 2.6 & Unbaited \\
\hline Victor Road & $33^{\circ} 16^{\prime} 10^{\prime \prime}$ & $116^{\circ} 00^{\prime} 49^{\prime \prime}$ & 930 & 8.2 & Unbaited \\
\hline
\end{tabular}

a Fox baiting occurs biannually since 1994 across wider, surrounding area as part of CALM's Western Shield/Operation Foxglove programme.

b Fox baiting occurs quarterly since 1994 across wider, surrounding area as part of CALM's Western Shield/Operation Foxglove programme. 
Quokkas were placed into three age classes: pouch young (restricted to the pouch); juveniles (i.e. permanently exited the pouch but not yet breeding); and adults. The birth dates of pouch young were estimated by comparing morphological measurements to growth curves (Shield and Woolley, 1961). Juveniles weighed between $550 \mathrm{~g}$ and adult body weight which was greater than $2.5 \mathrm{~kg}$ for males and $1.6 \mathrm{~kg}$ for females. This definition was based on observations of the reproductive status of individuals exceeding these weights, such as enlarged testes in males and the presence of pouch young for females, and this contrasts with previous studies (Dunnet, 1963; Sinclair, 1998).

New animals were fitted sub-cutaneously with a TROVAN ${ }^{\circledR}$ transponder microchip (Central Animal Records, Melbourne, Victoria). The hole resulting from the ear tissue sample taken for genetic analysis served as a secondary mark to ensure that no marks were missed or lost (an assumption of mark-recapture methods; White et al., 1982).

Animals were released near the point of capture once they regained full mobility and awareness (usually $1 \mathrm{~h}$ ). There was no mortality associated with animal handling or sedation although two adult females died within traps (pre-sedation).

\subsection{Data analysis}

Three methods of estimating actual and relative population size were used in order to allow comparison with other studies. Capture success was determined by the number of newly captured individuals divided by the number of available traps (that is, excluding all closed or occupied traps). The minimum number of individuals known to be alive was estimated, whereby an animal alive at the start and finish of the primary trapping periods was assumed to be alive between these periods (Krebs, 1966). Open population estimates were attained using the Jolly-Seber (J-S) method (Seber, 1982) in the computer program JOLLY. Actual population estimates are valid for this study as each site is thought to support discrete populations within the swamps (i.e. geographically closed). Program MARK (White and Burnham, 1999) was not used as a significant chisquared goodness of fit statistic would be anticipated with the small sample sizes from this study, irrespective of the validity of the model.

Estimators have been shown to produce low bias and high precision closed population estimates with small sample sizes when the models reflect the underlying population attributes (McKelvey and Pearson, 2001). Although our data are from open populations, we believe that with known mortality and no immigration, use of the of $\mathrm{J}-\mathrm{S}$ model is appropriate and provides more meaningful information to wildlife managers than crude relative indices of population size (see Anderson,
2001). All other assumptions of open population estimation were met (White et al., 1982) and population density was calculated as the number of individuals estimated by the $\mathrm{J}-\mathrm{S}$ method per hectare of swamp.

The recruitment of juveniles into the population was estimated by counting the number of pouch young per female multiplied by the number of females with pouch young (Gilfillan, 2001) over the entire study period. This was then compared with the number of juveniles actually captured to get a recruitment percentage (Gilfillan, 2001).

Statistical calculations were analysed using Statview Version 5.0 (SAS Institute Inc., 1998). In ANCOVA, where the slopes were not significantly different, interaction terms were deleted and the analyses recalculated to investigate differences in intercepts (Sokal and Rohlf, 1969). Significant comparisons were assessed with Scheffe's post-hoc test at 5\% significance level. The Rosella Road site was excluded from several analyses due to its small sample size.

\section{Results}

\subsection{Trapping success and population size}

More than 21,000 trap nights yielded 281 quokka captures of 95 individual animals, of which 62 were mature adults (Table 2). Quokka presence could not be confirmed by trapping or faecal pellet counts at two sites (Holyoake and Wild Pig Swamp) previously known to support them or at another site with suitable habitat and an unconfirmed sighting (Hoffman) (Table 2). This led to the early cessation of trapping at these sites.

Capture success at sites with quokkas present varied from 0.03 animals per 100 trap nights at Rosella Road to 0.99 at Hadfield (Table 2). The known to be alive estimates varied in a similar fashion, ranging from a lone male at Rosella Road to 21 individuals at Hadfield (Table 2). The $\mathbf{J}-\mathrm{S}$ estimates indicated that the Victor Road site had the smallest calculable population (9) and Kesners the largest (36), with the Rosella Road population being too small to calculate (Table 2). Based on the $\mathrm{J}-\mathrm{S}$ estimates, Hadfield supported the highest population density (over four adults per hectare), followed by Kesners, then Victor Road, Chandler Road and finally Rosella Road (Table 2). No individuals captured at one site were subsequently captured at another.

\subsection{Population composition}

The 95 captured quokkas were comprised of $50 \%$ adults, $25 \%$ juvenile individuals and $25 \%$ pouch young (Table 3). The proportion of adult, juvenile and pouch young in each population varied between the sites (Fig. 2) but not significantly (Contingency $\chi^{2}=9.341$; d.f. $=20 ; P=0.31)$. 
Table 2

Population estimates and capture success of adult quokkas at sites in the northern jarrah forest calculated for the entire study period. The high variability of quokka captures excluded presenting seasonal capture data

\begin{tabular}{|c|c|c|c|c|c|c|c|}
\hline Site & Trap nights & $\begin{array}{l}\text { Captures per } 100 \\
\text { trap nights }\end{array}$ & No. adults & $\begin{array}{l}\text { Known to } \\
\text { be alive }\end{array}$ & $\begin{array}{l}\text { Jolly } \\
(\mathrm{J}-\mathrm{S}) \pm \text { S.E. }\end{array}$ & $\begin{array}{l}\text { Density } \\
\text { (no. per ha.) }^{\text {a }}\end{array}$ & Recaptures \\
\hline Chandler Road & 4976 & 0.20 & 8 & 4 & $10 \pm 0$ & 0.9 & 11 \\
\hline Hadfield & 2592 & 0.99 & 21 & 21 & $29 \pm 5$ & 4.3 & 69 \\
\hline Hoffman & 368 & 0 & 0 & 0 & 0 & 0 & - \\
\hline Holyoake & 54 & 0 & 0 & 0 & 0 & 0 & - \\
\hline Kesners & 5842 & 0.40 & 21 & 11 & $36 \pm 6$ & 2.9 & 22 \\
\hline Rosella Road & 4607 & 0.03 & 1 & 1 & $\mathrm{~b}$ & $0.07^{\mathrm{c}}$ & 1 \\
\hline Victor Road & 2654 & 0.51 & 11 & 10 & $9 \pm 1$ & 1.1 & 78 \\
\hline Wild Pig & 194 & 0 & 0 & 0 & 0 & 0 & - \\
\hline Overall & 21287 & 0.42 & 62 & 47 & 84 & - & 186 \\
\hline
\end{tabular}

a Based on the $\mathbf{J}-\mathrm{S}$ estimate divided by the area of the swamp (Table 1).

b Population size at Rosella Road was too small to calculate using J-S method.

c Based on one captured individual known to be alive through telemetry.

Table 3

Sex ratios of all newly captured quokkas recorded at sites in the northern jarrah forest. Only sites with more than one individual known to be alive were used

\begin{tabular}{lcccl}
\hline Site & \multicolumn{4}{l}{ Number of each sex $(\mathrm{M}: \mathrm{F})$} \\
\hline & Adults & Juveniles & Pouch young & Overall sex ratio \\
\cline { 2 - 5 } Chandler Road & $3: 2$ & $1: 1$ & $0: 1$ & $1.0: 1.0$ \\
Hadfield & $6: 11$ & $4: 3$ & $7: 4$ & $1.0: 1.1$ \\
Kesners & $10: 6$ & $5: 5$ & $0: 3$ & $1.1: 1.0$ \\
Victor Road & $5: 4$ & $3: 1$ & $5: 4$ & $1.4: 1.0$ \\
Overall & $24: 23$ & $13: 10$ & $12: 12$ & $1.1: 1.0$ \\
\hline
\end{tabular}

There was no significant variation from parity for the sexes overall ( 50 males -45 females $G=0.35$; d.f. $=1$; $0.75>P>0.50$ ) or at each age class (Contingency $\chi^{2}=0.212$; d.f. $\left.=2 ; P=0.90\right)$ (Table 3). There was also no significant variation from parity of the sexes at each site (Contingency $\chi^{2}=17.579 ; \quad$ d.f. $=20 ; \quad P=0.62$ ) (Table 3).

\subsection{Morphology and condition}

Body mass of adult quokkas from the northern jarrah forest exhibited sexual dimorphism with males significantly larger than females (two-factor ANOVA of $\log _{10}$ transformed body mass $F_{1,48}=45.234, P<0.0001$ ) (Table 4). The heaviest male captured weighed $4.79 \mathrm{~kg}$ while the heaviest female weighed $3.38 \mathrm{~kg}$. There was no significant difference between sites in adult body mass $\left(F_{3,48}=0.738, P=0.535\right)$ or mass of consecutively captured animals between the seasons (single factor (sex) repeated measures ANOVA $F_{3,18}=1.28, P=0.331$ ) (Fig. 3).

Tail circumference was used as an indicator of the condition of quokkas and it differed significantly between adult males and females (ANCOVA $F_{1,48}=$
11.17, $P=0.0017)$, however these slopes were significantly different $(P=0.0013)$. Increase in tail circumference compared to body weight was twice as rapid in males (regression $r^{2}=0.78$; slope $=0.4 ; n=26 ; P<0.0001$ ) as females $\left(r^{2}=0.26\right.$; slope $\left.=0.2, n=26 ; P<0.0001\right)$. There was a significant difference in tail circumference between sites after adjusting for differences in body mass (ANCOVA $F_{3,48}=9.24 ; P<0.0001$ ) when the sexes were pooled. Animals at Chandler and Kesners had significantly larger tail circumferences than those at Hadfield and Victor Road (Scheffe's test $P<0.03$ for each). There were significant differences in tail circumference between seasons for repeatedly captured individuals (repeated measures ANOVA $F_{3,18}=4.091 ; P=0.022$ ), with animals having significantly larger tail circumferences in autumn than in winter (Scheffe's test $P=0.03$ ). There were not enough data to compare seasonal variation in tail circumference between the sexes using repeated measures ANOVA. Tail circumference peaked in summer and was lowest in winter for males and spring for females (Fig. 4). There was an increase in tail circumference for females in summer (Fig. 4) whereas body mass increased in winter (Fig. 3). Similarly, where both sexes increased body mass in winter, tail circumference declined (Fig. 4). There was no correlation between tail circumference and population size (regression $r^{2}=0.001 ; n=95$ for all; $\left.P=0.818\right)$, density $\left(r^{2}=0.014\right.$; $P=0.412)$, swamp length $\left(r^{2}=0.016 ; \quad P=0.388\right)$ or swamp area $\left(r^{2}=0.043 ; P=0.147\right)$.

\subsection{Reproduction}

There were 56 captures of 47 adult female quokkas (new or recaptured from a previous trapping session), however less than half of these individuals (23) were recorded as breeding at the time of capture via lactation or the presence of pouch young. All exhibited elongated 


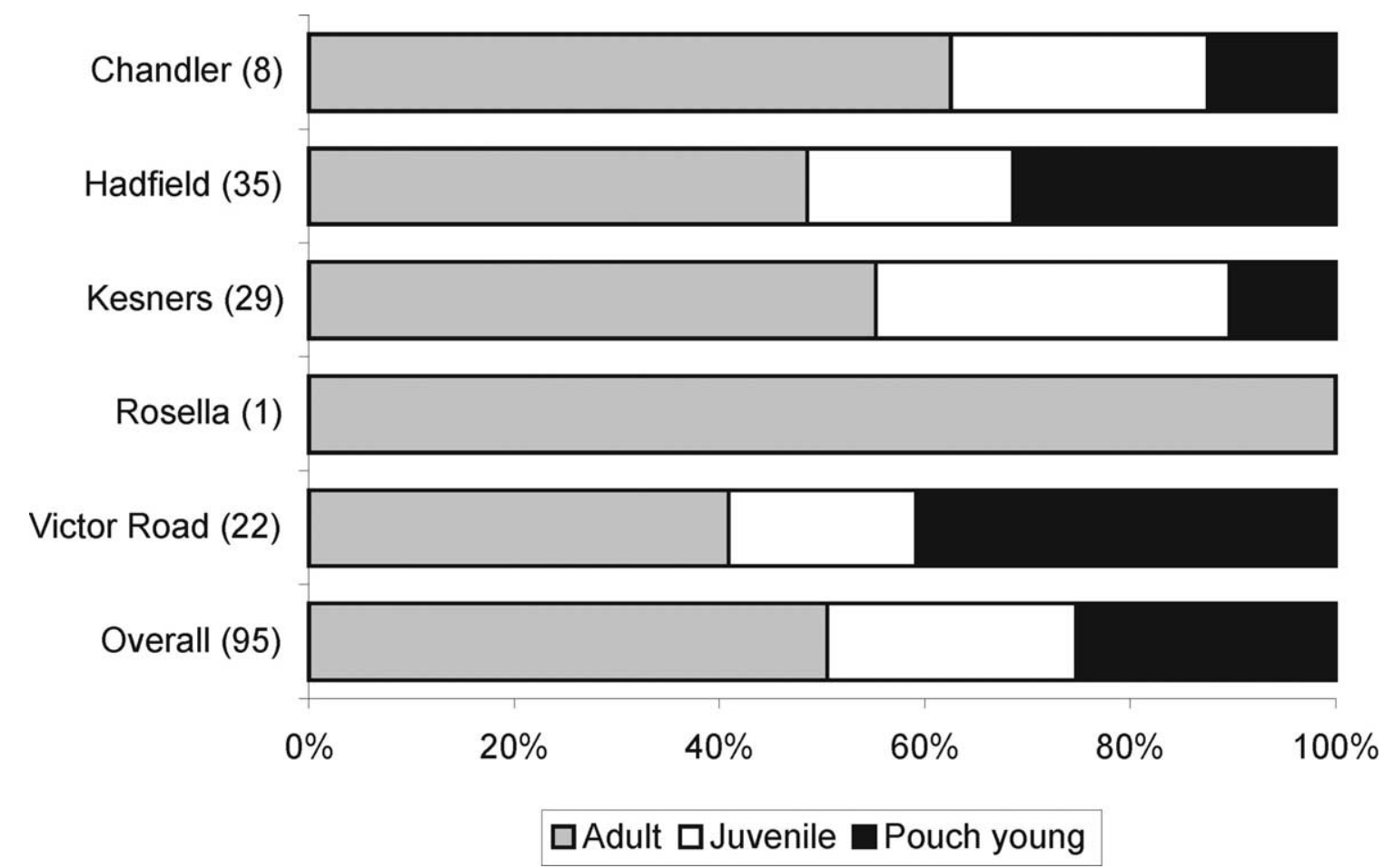

Fig. 2. Age class breakdown (\%) of quokkas at first capture for sites in the northern jarrah forest. Only sites with quokkas are shown. Numbers in parentheses show the total number of individuals recorded.

Table 4

Mean body mass of quokkas from sites in the northern jarrah forest

\begin{tabular}{llll}
\hline Site & $\begin{array}{l}\text { Male mean } \\
(\mathrm{kg}) \pm \text { S.E. }\end{array}$ & $\begin{array}{l}\text { Female mean } \\
(\mathrm{kg}) \pm \text { S.E. }\end{array}$ & $\begin{array}{l}\text { Overall mean } \\
(\mathrm{kg}) \pm \text { S.E. }\end{array}$ \\
\hline Chandler Road & $3.54 \pm 0.15$ & $2.47 \pm 0.23$ & $3.18 \pm 0.21$ \\
Hadfield & $3.81 \pm 0.13$ & $2.73 \pm 0.07$ & $3.12 \pm 0.10$ \\
Kesners & $3.85 \pm 0.13$ & $2.18 \pm 0.18$ & $3.37 \pm 0.18$ \\
Victor Road & $3.43 \pm 0.15$ & $2.74 \pm 0.06$ & $3.02 \pm 0.09$ \\
Overall & $3.68 \pm 0.07$ & $2.65 \pm 0.05$ & $3.16 \pm 0.07$ \\
\hline
\end{tabular}

teats that signified previous breeding. Eighty-four per cent of these females had pouch young of various ages, ranging from $100 \%$ at Chandler $(n=2)$ and Kesners $(n=9)$ to $88 \%$ at Hadfield $(n=26)$ and $68 \%$ at Victor Road $(n=19)$. The differences between sites were not significant $\left(\chi^{2}=1.596\right.$, d.f. $\left.=3,0.75<P<0.50\right)$. There was no significant relationship between the proportion of females with young and population size (regression $r^{2}=0.22 ; n=4$ for both; $P=0.53$ ) or population density $\left(r^{2}=0.04 ; P=0.80\right)$. Adult females that were captured each season throughout the study averaged 2.2 young per year (Victor Road mean $=2.15$; ranging up to 2.40 at Hadfield). Out of six females captured four times or more over 18 months, four had three consecutive young (in pouch or at foot) and two had two young. No twins were observed.
The youngest female to give birth was 15 months old and weighed $1.65 \mathrm{~kg}$ and another female of known birth date had a pouch young when trapped at 18 months of age. The average mass of breeding females was $2.77 \pm 0.05 \mathrm{~kg}$. The testes of males were noticeably enlarged and conspicuous when body mass exceeded 2.5 $\mathrm{kg}$.

In this study, births were far more evenly distributed throughout the year than for quokkas on Rottnest Island (Shield, 1964) (Fig. 5), however they were still not uniformly distributed (Kolmogorov-Smirnov test $D=0.19$, d.f. $=57,0.02<P<0.05)$. When these data were pooled by season, the variation was even more significant $(D=0.35$, d.f. $=57, P<0.001)$ with summer being the season of fewest births (Fig. 5). The addition of 31 mainland births (Shield and Woolley, 1963) made no changes to these trends with summer births still occurring at approximately half the rate of the other seasons (summer 12 births, autumn 28, winter 24 and spring 24).

The number of juveniles expected to enter the total quokka population over the study period was 47 . The number of juveniles observed entering the population was 19 which represents a $40 \%$ recruitment rate of pouch young to adult. This was significantly less than expected $\left(\chi^{2}=19.62\right.$; d.f. $\left.=3 ; P<0.0001\right)$. The percentage rate of recruitment differs between the sites with Kesners having the highest rate $(89 \%)$, then Chandler $(50 \%)$, Victor Road (38\%) and Hadfield (22\%). 


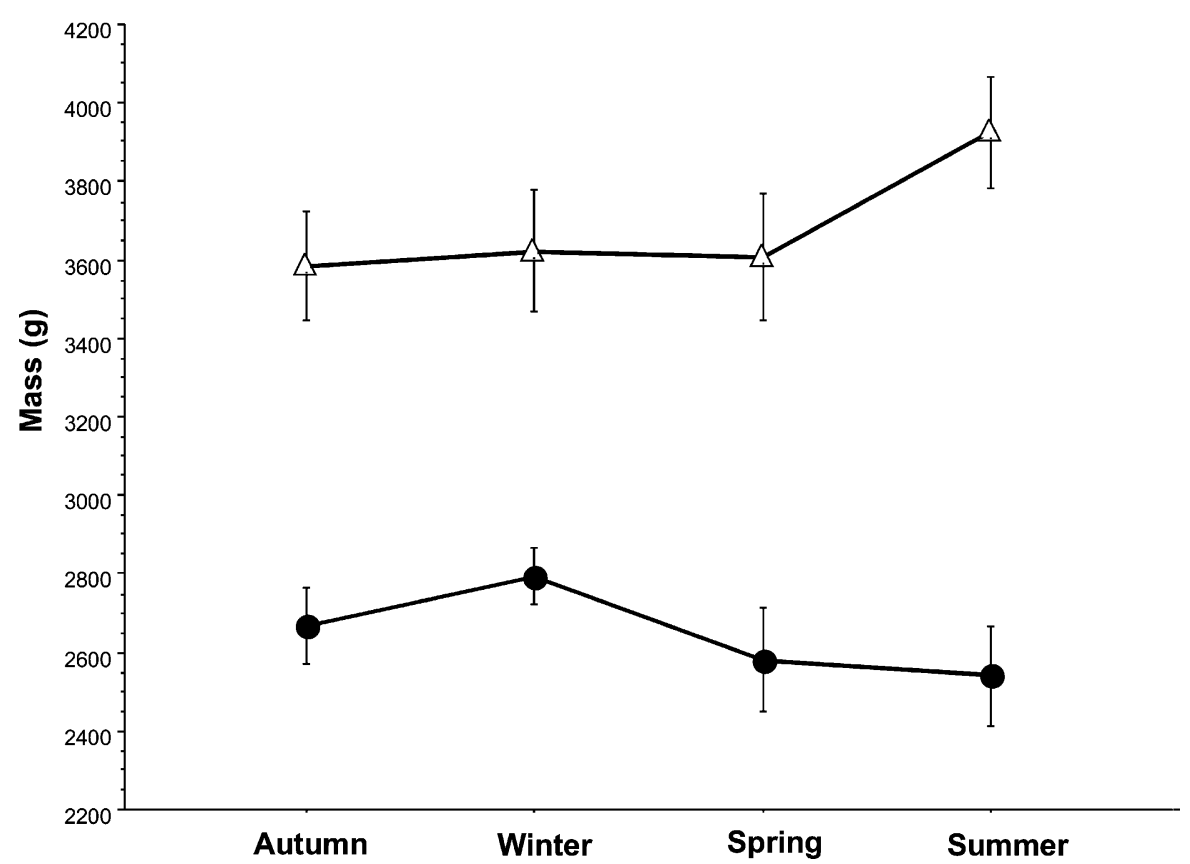

Fig. 3. Seasonal variation in mass (mean \pm S.E. in $g)$ of male $(n=57)$ (triangles) and female $(n=58)$ (circles) quokkas from sites in the northern jarrah forest.

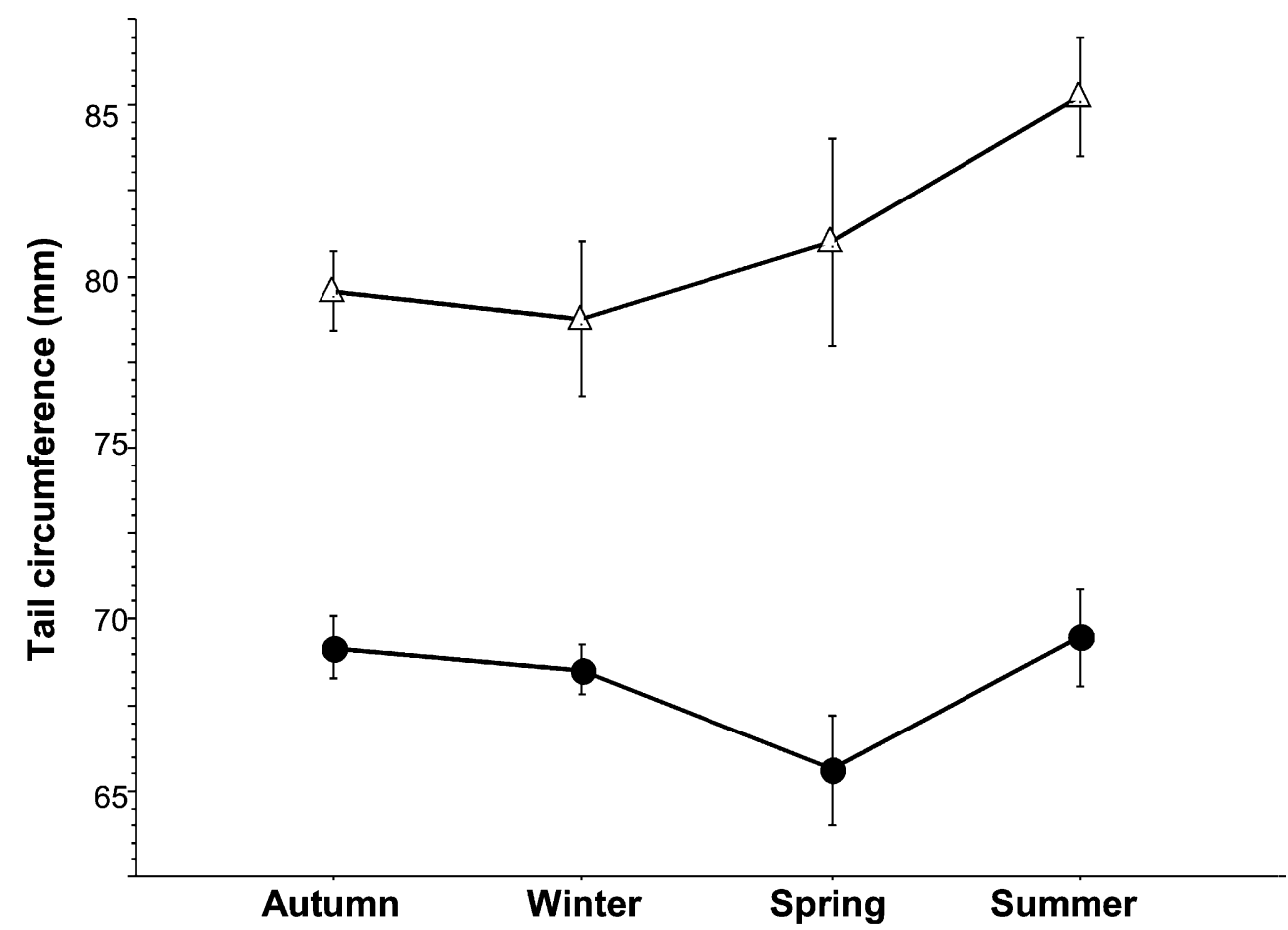

Fig. 4. Seasonal variation (mean \pm S.E.) in quokka tail circumference (a measure of condition). Males are shown as triangles and females as circles.

\section{Discussion}

\subsection{Population sizes}

This study confirmed the anecdotal reports of the low abundance of local quokka populations in the northern jarrah forest. The widely scattered populations rarely exceed 30 individuals and have a maximum density of four quokkas per hectare within small and isolated habitat patches. Considering the paucity of recent museum records (Western Australia Museum personal communication) and the reports of population declines 


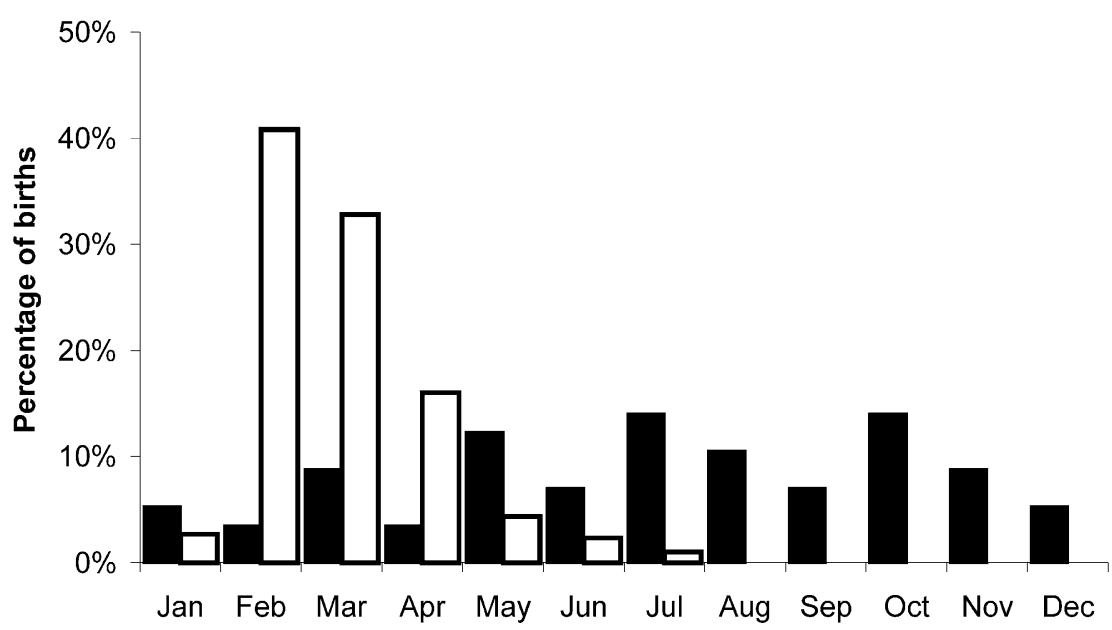

Fig. 5. Percentage of quokkas born each month in the northern jarrah forest (this study) (black) ( $n=57)$ and Rottnest Island (unfilled) ( $n=299$ taken from Shield, 1964).

elsewhere (Maxwell et al., 1996), some concern should also be raised for quokka populations in areas south of the northern jarrah forest.

Further surveys will probably identify additional populations, however the total adult quokka population in the northern jarrah forest may be as few as 150 individuals. This includes the 84 individuals estimated in this study, as well as estimates for the Gervasse and Albany Highway populations. Gervasse is a relatively high density site with a population estimated at 48 individuals (PdeT unpublished data). The scats and runways present at the Albany Highway site suggest a moderate population size $(\sim 15)$ when compared to the trapped sites (MWH unpublished data). Only half of this overall known population of 150 is likely to be breeding females.

Quokkas appear to be locally extinct or on the verge of localised extinction at four of the eight sites that were trapped (Holyoake, Wild Pig Swamp, Hoffman and Rosella Road). Only one male was trapped at the Rosella Road site whereas trapping in 1997 yielded two (A. Tomkinson personal communication) and in 1995 yielded four other individuals (PdeT unpublished data). Local extinction here appears imminent. Quokkas were captured at Holyoake in the early 1990s, yet by 1995 the population was believed to be extinct (PdeT unpublished data). This site is within $1 \mathrm{~km}$ of the Dwellingup residential and agricultural areas and this proximity and associated disturbance may have affected the quokkas there. A sizeable population of quokkas persisted at Wild Pig Swamp in the early 1990s and evidence of their continued presence was detected in 1995 but was unable to be confirmed by trapping (PdeT unpublished data). The absence of scats, the deterioration of runways and the lack of captures during this study suggests another localised extinction. Activity associated with bauxite mining has occurred to within $20 \mathrm{~m}$ of the swamp around the upper reaches of this site and this disturbance may have contributed to the local decline. Although possessing areas of Agonis-dominated habitat and having an unconfirmed sighting in 1998 (A. Danks, personal communication), the Hoffman site showed no evidence of quokka presence (scats/runways/captures).

The small population estimates at the Chandler and Victor Road sites also suggest a significant threat of localised extinction. Even the two largest populations estimated in this study (Kesners and Hadfield) are well below the minimum viable population size (50) often speculated as delineating genetic problems such as inbreeding depression and loss of heterozygosity (Caughley, 1994).

At Barker's Swamp on Rottnest Island, the population density of quokkas between December 1967 and December 1969 was 16.7 quokkas per hectare (Kitchener, 1973). This was far greater than was recorded for the whole island where density was reported to be between 0.8 and 2.5 per hectare (Main and Yadav, 1971) which is similar to that found on the mainland. This exceptionally high density around Barker's Swamp was attributed to recruitment of individuals to the valuable water resource (Kitchener, 1973). Kitchener (1973) determined that an area of between 120 and 360 ha was necessary to support a sustainable quokka population, however in resource-rich areas, such as around fresh water, he revised this area to as little as 18 ha. Despite being relatively resource-rich, none of the swamps studied in the northern jarrah forest covered an area as large as 18 ha (Table 1). This suggests that local populations on the mainland were not reproductively isolated historically. Considering the past reports of high quokka density on the mainland (e.g. White, 1952), the densities reached at resource-rich areas on Rottnest Island and the relative stability of the patch sizes, it seems that the quokka populations investigated in this 
present study are well below the carrying capacity of each site.

\subsection{Quokkas and their response to fox control}

Perhaps the biggest concern of the small population sizes is that there is no evidence to suggest populations have shown a response to the on-going fox control. Fox control began in the northern jarrah forest in June 1994 and additional high-intensity baiting commenced at quokka sites between October 1997 and March 1999 (Table 1). Fox baiting within the northern jarrah forest has been shown to result in significantly higher levels of survivorship of predation-sensitive species at sites with higher baiting frequencies (de Tores, 1999). In other parts of Western Australia, fox control has been shown to result in dramatic increases in native fauna abundance (Christensen, 1980; Kinnear et al., 1988; Friend, 1990; Morris, 1992; de Tores, 1999). For example, highintensity fox control was initiated at two reserves in the Western Australian wheatbelt in 1982 and within 2 years the low density population of black-footed rockwallabies (Petrogale lateralis) had almost doubled (Kinnear et al., 1988). After 8 years these populations had increased by up to $400 \%$ (Kinnear et al., 1998). Considering the similarity in fecundity (Sharman and Maynes, 1995) and initial population size between quokkas and black-footed rock-wallabies, it could be anticipated that, with the easing of predation pressure, quokka numbers would increase in a similar fashion to that observed in the rock-wallabies.

Quokkas may have an even greater propensity to increase than rock-wallabies considering fox control in the jarrah forest is likely to have led to population increases in other critical weight range mammals (e.g. common brushtail possum Trichosurus vulpecula, southern brown bandicoot Isoodon obesulus and chuditch Dasyurus geoffroii). With these species increasing in abundance relative to both the quokka and the fox, it is anticipated that the fox would functionally shift its prey species preferences to them which, in turn, would exert even less predation pressure on quokkas. Nonetheless, as a classic alternate prey species, the quokka is still likely to be vulnerable below threshold populations of about 50 animals (Sinclair et al., 1998).

Some caution must be exercised if concluding quokka populations within the northern jarrah forest have not responded to fox control however. The longevity of high-intensity fox control (maximum of 4 years) may have meant that quokka populations have only just begun the exponential increases observed in rock-wallabies (Kinnear et al., 1988). Given the 'threatened' conservation status of the quokka, management of known sites has been in accordance with the precautionary principle and all but one of these sites is regularly baited to control foxes. Consequently, the experimental design of the current project was such that direct statistical comparison between treatment and control sites was impossible. While no firm conclusions can be made regarding the quokkas' need for fox control, the absence of detectable population increases at the treatment sites suggests either fox predation does not limit population growth, the level of fox control may be insufficient or it has not been on-going for long enough to enable a response. Given the response of other predation sensitive species (de Tores, 1999), the fecundity of the quokka and the current level of fox control in the northern jarrah forest, it seems unlikely therefore that fox predation alone is limiting quokka population growth. Considering the quokkas' apparent preference for a mosaic of seral stages within the Agonis swamps (Christensen and Kimber, 1975), the absence of a detectable increase in quokka population size may reflect more specific habitat requirements in addition to predator limitation.

\subsection{Population composition}

The age-class structure of quokkas on the mainland (50\% adult, $25 \%$ juvenile, and $25 \%$ pouch young) was very similar to that observed by Dunnet (1963) on Rottnest Island (49\% adult, $22 \%$ juvenile and $29 \%$ pouch young). This suggests that mortality rates through all age classes are similar between the two regions which is not surprising given the seasonal starvation that afflicts the Rottnest population (Waring, 1956, 1959) and the likely predation rates on the mainland.

The differences among sites in age-class breakdown (Fig. 2) may reflect future population growth and therefore the 'health' of a population. A preponderance of breeding adults suggests catastrophic events may have removed old and young animals from the population while an abundance of sub-adults suggests a high reproductive output and therefore population growth (p. 254 in Caughley and Sinclair, 1994). With the highest proportion of juveniles and pouch young, Victor Road appears to be the site with the greatest propensity to increase, followed by Hadfield. The Kesners site has very few pouch young which may indicate that the site is approaching carrying capacity or has experienced a recent catastrophic event. The Chandler site has a much lower proportion of sub-adults and this may indicate it is a population in decline. Factors inhibiting the rate of increase of quokka populations appear to be acting in increasing order of severity from Victor Road and Hadfield to Kesners, Chandler and then Rosella Road. As the Victor Road site is unbaited it reinforces the suggestion that habitat features may be as important as predation in inhibiting quokka population growth. Yet the overall level of recruitment following weaning is low $(40 \%)$ and increases from Hadfield $(22 \%)$ to Victor Road then Chandler and finally Kesners (89\%) with the highest recruitment rate. This order is almost opposite 
to that of the overall population composition (Fig. 2) and may partially explain the apparent population decline despite fox control.

\subsection{Body condition}

While the validity of condition indices has been questioned (Krebs and Singleton, 1993), its use has been accepted in many studies including those on quokkas which have been shown to possess caudal fat deposits (Miller and Bradshaw, 1979; Bakker and Main, 1980). The seasonal variation in tail circumference observed in this study concurs with these previous findings. Male fat storage peaked in summer at the end of the high rainfall months whereas female tail circumference remained relatively constant throughout the year but with a decline in spring. This decline in female fat content following winter may be caused by the costs of maintaining body heat, as occurs in the mountain brushtail possum (Trichosurus caninus; Viggers et al., 1998). The more rapid growth of tail circumference for males over summer (Fig. 4) suggests also that the higher costs of reproduction in females may be reducing their ability to store fat and that they only do so following the period of reduced breeding over summer (Fig. 5).

\subsection{Reproduction}

The age of first breeding for females in this study (15 months) was much older than that observed in captive quokkas (8-9 months; Shield, 1968) but younger than Rottnest Island (18-30 months; Shield, 1964). Captive males start breeding at 12-13 months (Shield, 1968) but on Rottnest Island at over two years (Shield, 1964).

Although female quokkas on Rottnest Island have occasionally been observed with twins (Shield, 1964) none were detected in this study. With 185 to 200 days from birth to weaning in quokkas (Sharman, 1955a, b; Shield, 1968), it is possible for a female to produce 1.825 to two young per year. Based on an initiation of breeding at 18 months (Shield, 1964, 1968) and a longevity of 10 years (Holsworth, 1964; Shield, 1968) female quokkas are able produce up to 17 young over a lifetime. While possible on the mainland, the seasonal anestrous on Rottnest Island means that breeding generally only occurs once a year and begins at two and a half years of age (Shield, 1964). A total of seven or eight young over a lifetime is more realistic for the island population. The higher fecundity on the mainland means there is a high capacity to increase population size, however this was not observed despite the relaxation of predation pressure.

Female quokkas captured seasonally in the northern jarrah forest averaged 2.2 births per year which is more than we have just determined is mathematically possible. This may be explained by the death of pouch young prior to weaning and their subsequent replacement from a blastocyst. A high rate of pouch young mortality is reinforced by the low percentage of juveniles recruited into the population. This study has found that less than one in two pouch young survived to independence. This may also explain the continued low population levels. Aging individuals proved too difficult as only minor sedation was used in the field, so we have no data on whether this low reproductive output is attributable to the reproductive senescence of old individuals. Predation by foxes is responsible for up to $35 \%$ of juvenile mortality in eastern grey kangaroos (Macropus giganteus) which substantially limits recruitment (Banks et al., 2000) and, in association with habitat requirements, may be affecting quokkas in a similar manner.

Quokkas on Rottnest and Bald Islands breed seasonally with the majority of births occurring between February and April (Fig. 5; Shield, 1964). This seasonal pattern of breeding was attributed to the seasonal variation in climate causing starvation which induced anestrous (Shield, 1964). This pattern is thought to have evolved to provide the young with high nutrient forage at weaning following the winter rains (Shield and Woolley, 1963).

Breeding season differences have been observed in other macropods also (Merchant and Calaby, 1981; Robertshaw and Harden, 1986). Predation pressure by dingoes (Canis lupus dingo) on swamp wallabies (Wallabia bicolor) caused them to breed throughout the year whereas nearby conspecifics under lower predation pressure breed seasonally (Robertshaw and Harden, 1986). This may arise when females are harassed by dingoes and expel their pouch young as a predator avoidance strategy. These young are replaced from blastocysts and year-round breeding occurs. However, the fact that annual breeding in Rottnest quokkas can be induced in captivity through the provision of adequate nutrition (Shield, 1964, 1968) suggests factors other than predation regulate this. This is reinforced by observations of quokkas inhabiting the rubbish tip on Rottnest Island that breed throughout the year due to the predictable abundance of food compared to their seasonally starved neighbours (Shield, 1964). The unique mode of reproduction in marsupials means that they can readily terminate the most energetically costly phases of reproduction if resources become limiting (Parker, 1977; Robertshaw and Harden, 1989). The continuous breeding of quokkas on the mainland suggests nutrients are not limiting and therefore the low recruitment rate indicates predation is still inhibiting the anticipated population increase.

\section{Conclusion}

It seems unlikely that the quokka population in the northern jarrah forest was originally pan-mixic and now reflects a preference for predation refugia given historical 
reports of its restriction to specific habitat patches (White, 1952; Gould, 1973). The plight of the quokka on the mainland can therefore be considered from a metapopulation dynamics perspective. There are very few examples in the literature of larger mammals occurring naturally as metapopulations see review by (Hastings and Harrison, 1994; Elmhagen and Angerbjorn, 2001). Difficulties in identifying such metapopulations stem from the large temporal scales needed to record population turnover through localised extinction and colonisation with patch occupancy data (Elmhagen and Angerbjorn, 2001). The restriction to discrete habitat patches and the absence of correlation in life history characteristics between populations (e.g. Fig. 2) are recommended by Elmhagen and Angerbjorn (2001) to illustrate such metapopulations. Consequently, it seems likely that the quokka once naturally existed as a classic metapopulation (as defined by Hanski and Gilpin, 1991), being restricted to abundant but discrete habitat patches wherein breeding took place and ecological processes, including colonisation and extinction, were uncorrelated while functioning on a local and regional scale (Hanski, 1999). This patchiness was not caused by human-induced habitat fragmentation, but rather arose through the occurrence of naturally occurring islands of the quokkas' preferred habitat (Christensen and Kimber, 1975).

The northern jarrah forest quokka metapopulation was subsequently threatened through predation and habitat alteration arising from fire regimes that no longer produced a mosaic of seral stages (Gardner, 1957). Turnover of local populations subsequently resulted in a negative feedback relationship as the species declined and local populations became extinct. This resulted in a non-equilibrium metapopulation in which local extinction dominated as part of the species overall decline (Harrison, 1991).

The northern jarrah forest quokka metapopulation structure today is characterised by excessively large inter-patch distances, such that the metapopulation persistence time (Hanski and Gilpin, 1991) appears very short with few populations remaining and those that remain reduced to very low numbers. Further, the likelihood of localised extinction appears high as there is little potential for a 'rescue effect' from immigrants (Brown and Kodric-Brown, 1977) as distances of up to $40 \mathrm{~km}$ separate extant populations. Such non-equilibrium metapopulations are generally bound for regional extinction (Harrison, 1991) as the overall metapopulation collapses.

Given local extinction has a greater bearing on metapopulation persistence time than colonisation rate (Etienne and Heesterbeek, 2001) the approach we recommend is to manage known populations of quokkas in the northern jarrah forest as separate entities rather than a metapopulation (Hastings and Harrison, 1994) until its structure is restored. This is recommended in preference to augmenting these populations with translocated animals from Rottnest Island given the genetic differences between island and mainland populations (Sinclair, 2001). We stress that management is required as the metapopulation is unlikely to restore itself otherwise particularly in light of the low population sizes and recruitment rates.

Managing populations as separate entities involves identifying all sites containing quokkas, increasing quokka density through natural, in situ processes, combined with feral predator control and habitat manipulation to increase the number of potential sites and increase their connectivity. Clearly for this to occur, all threatening processes must be identified and removed to the extent that each extant population can act as the source for natural colonisation to adjacent habitat patches. Monitoring is also a critical component and such programmes should ensure changes in population size and structure can be detected. If our theory of a quokka metapopulation is correct then we would expect longerterm monitoring to show increasing population densities followed by an increased patch occupancy rate surrounding source populations.

\section{Acknowledgements}

We thank R. Brazell, P. Banks and T. Dawson for helpful discussions on quokkas. L. Wright obtained many of the references. We also thank the numerous volunteers for trapping assistance. Trapping permits were issued by CALM (License number SF002928). Ethics approval was CALM Animal Experimentation Ethics Committee approval CAEC 1/97 and subsequent renewals. J. Hayward, J. Taylor, K. Ross, M. Augee, P. Banks, M. Williams, N. Marlow, N. Burrows, A.H. Burbidge and E. Jefferys provided valuable comments on this paper. This project was funded by the Western Australian Department of Conservation and Land Management (CALM) and Alcoa of Australia. The support of CALM's former Executive Director, Dr. Syd Shea, is greatly appreciated. MWH was supported by a University of New South Wales Postgraduate Research Award which was transferred to an Australian Postgraduate Award.

\section{References}

Anderson, D.R., 2001. The need to get the basics right in wildlife field studies. Wildl. Soc. Bull. 29, 1294-1297.

Bakker, H.R., Main, A.R., 1980. Condition, body composition and total body water estimation in the quokka, Setonix brachyurus (Macropodidae). Aust. J. Zool. 28, 395-406.

Banks, P.B., Newsome, A.E., Dickman, C.R., 2000. Predation by red foxes limits recruitment in populations of eastern grey kangaroo. Austral Ecol. 25, 283-291. 
Barker, S., Main, A.R., Sadlier, R.M., 1957. Recent capture of the quokka (Setonix brachyurus) on the mainland. W.A. Nat. 6, 5355 .

Baverstock, P.R., Richardson, B.J., Birrell, J., Krieg, M., 1989. Albumin immunologic relationships of the Macropodidae (Marsupialia). Syst. Zool. 38, 38-50.

Beard, J.S., 1980. A new phytogeographic map of Western Australia. W.A. Herb. Res. Notes 3, 37-58.

Brown, J.H., Kodric-Brown, A., 1977. Turnover rates in insular biogeography: effect of immigration on extinction. Ecology 58, 445449.

Burk, A., Westerman, M., Springer, M.S., 1998. The phylogenetic position of the musky rat-kangaroo and the evolution of bipedal hopping in kangaroos (Macropodidae: Diprodontia). Syst. Biol. 47, 457-474.

Caughley, G., 1994. Directions in conservation biology. J. Anim. Ecol. 63, 215-244

Caughley, G., Sinclair, A.R.E., 1994. Wildlife Ecology and Management. Blackwell Science, Massachusetts, USA.

Christensen, P.E.S., 1980. The Biology of Bettongia penicillata Gray, 1837, and Macropus eugenii (Desmarest, 1817) in Relation to Fire (Rep. No. 91). Forests Department of Western Australia, Perth, Western Australia.

Christensen, P.E.S., Annels, A., Liddelow, G., Skinner, P., 1985. Vertebrate fauna in the southern forests of Western Australia (Rep. No. 94).. Forests Department of Western Australia, Perth.

Christensen, P.E.S., Kimber, P.C., 1975. Effect of prescribed burning on the flora and fauna of south-western Australian forests. Proc. Ecol. Soc. Aust. 9, 85-106.

de Tores, P., 1994. Fox Control Manual-operational guidelines for control of the red fox, Vulpes vulpes, through the use of Sodium monofluoroacetate or ' 1080 ' on CALM managed estate and in other CALM programs. Western Australian Department of Conservation and Land Management, Perth.

de Tores, P., 1999. Control and Ecology of the Red Fox in Western Australia-prey response to 1080 baiting over large areas. CALMScience, Wildlife Research Centre, Department of Conservation and Land Management, Western Australia: Wanneroo.

Dunnet, G.M., 1962. A population study of the quokka, Setonix brachyurus (Quoy \& Gaimard) (Marsupialia). II. Habitat, movements, breeding and growth. Wildl. Res. 7, 13-32.

Dunnet, G.M., 1963. A population study of the quokka, Setonix brachyurus Quoy \& Gaimard (Marsupialia). III. The estimation of population parameters by means of the recapture technique. Wildl. Res. 8, 78-117.

Elmhagen, B., Angerbjorn, A., 2001. The applicability of metapopulation theory to large mammals. Oikos 94, 89-100.

Etienne, R.S., Heesterbeek, J.A.P., 2001. Rules of thumb for conservation of metapopulations based on a stochastic winking-patch model. Am. Nat. 158, 389-407.

Friend, J.A., 1990. The numbat Myrmecobius fasciatus (Myrmecobiidae): history of decline and potential for recovery. Proc. Ecol. Soc. Aust. 16, 369-377.

Gardner, C.A., 1957. The fire factor in relation to the vegetation of Western Australia. W.A. Nat. 5, 166-173.

Gilfillan, S., 2001. An ecological study of a population of Pseudantechinus macdonnellensis (Marsupialia: Dasyuridae) in central Australia. II. Population dynamics and movements. Wildl. Res. 28, 481-492.

Gould, J., 1973. Kangaroos. The Macmillan Company of Australia Pty Ltd, Melbourne.

Hanski, I., 1999. Metapopulation Ecology. Oxford University Press, UK.

Hanski, I., Gilpin, M., 1991. Metapopulation dynamics: brief history and conceptual domain. Biol. J. Linn. Soc. 42, 3-16.

Harrison, S., 1991. Local extinction in a metapopulation context: an empirical evaluation. Biol. J. Linn. Soc. 42, 73-88.
Hastings, A., Harrison, S., 1994. Metapopulation dynamics and genetics. Ann. Rev. Ecol. Syst. 25, 167-188.

Heddle, E.M., Loneragan, O.W., Havel, J.J., 1980. Vegetation complexes of the Darling system, Western Australia. In: Atlas of Natural Resources, Darling System, Western Australia. Department of Conservation and Environment, Perth, Western Australia, pp. 3772.

Hilton-Taylor, C., (Compiler), 2000. 2000 Red List of Threatened Species. International Union for the Conservation of Nature and Natural Resources (IUCN), Gland, Switzerland.

Holsworth, W.N., 1964. Marsupial Behaviour with Special Reference to Population Homeostasis in the Quokkas on the West End of Rottnest Island. PhD Thesis, University of Western Australia, Nedlands, Western Australia.

King, D.R., Oliver, A.J., Mead, R.J., 1981. Bettongia and fluoroacetate: a role for 1080 in fauna management. Wildl. Res. 8, 529536.

King, D.R., Smith, L.A., 1985. The distribution of the European red fox (Vulpes vulpes) in Western Australia. Rec. W.A. Mus. 12, 197205.

Kinnear, J.E., Onus, M.L., Bromilow, R.N., 1988. Fox control and rock-wallaby population dynamics. Aust. Wildl. Res. 15, 435-450.

Kinnear, J.E., Onus, M.L., Sumner, N.R., 1998. Fox control and rock-wallaby population dynamics-II. An update. Wildl. Res. 25, $81-88$.

Kirsch, J.A.W., Lapointe, F.-J., Foeste, A., 1995. Resolution of portions of the kangaroo phylogeny (Marsupialia: Macropodidae) using DNA hybridization. Biol. J. Linn. Soc. 55, 309-328.

Kitchener, D.J., 19721972. The importance of shelter to the quokka, Setonix brachyurus (Marsupialia), on Rottnest Island. Aust. J. Zool. 20, 281-299.

Kitchener, D.J., 1973. Notes on home range and movement in two small macropods, the potoroo (Potorous apicalis) and the quokka (Setonix brachyurus). Mammalia 37, 231-240.

Kitchener, D.J., 1995. Quokka (Setonix brachyurus). In: Strahan, R. (Ed.), Mammals of Australia. Reed Books, Sydney, Australia, pp. 401-403.

Kitchener, D.J., Vicker, E., 1981. Catalogue of modern mammals in the Western Australian Museum 1895 to 1981. The Western Australian Museum, Perth.

Krebs, C.J., 1966. Demographic changes in fluctuating populations of Microtus californicus. Ecol. Monogr. 36, 239-273.

Krebs, C.J., Singleton, G.R., 1993. Indices of condition for small mammals. Aust. J. Zool. 41, 317-323.

Main, A.R., Yadav, M., 1971. Conservation of macropods in reserves in Western Australia. Biol. Cons. 3, 123-133.

Maxwell, S., Burbidge, A.A., Morris, K.D., 1996. The Action Plan for Australian Monotremes and Marsupials. Wildlife Australia, Canberra.

McKelvey, K.S., Pearson, D.E., 2001. Population estimation with sparse data: the role of estimators versus indices revisited. Can. J. Zool. 79, 1754-1765.

Mead, R.J., Twigg, L.E., King, D.R., Oliver, A.J., 1985. The tolerance to fluoroacetate of geographically separated populations of the quokka (Setonix brachyurus). Aust. Zool. 21, 503-511.

Merchant, J.C., Calaby, J.H., 1981. Reproductive biology of the rednecked wallaby (Macropus rufogriseus banksianus) and Bennett's wallaby (M. r. rufogriseus) in captivity. J. Zool. (Lond.) 194, 203217.

Miller, T., Bradshaw, S.D., 1979. Adrenocortical function in a field population of a macropodid marsupial (Setonix brachyurus, Quoy and Gaimard). J. Endocrin. 82, 1159-170.

Morris, K.D., 1992. Return of the chuditch. Landscope 8, 10-15.

Parker, P., 1977. An ecological comparison of marsupial and placental patterns of reproduction. In: Stonehouse, B., Gilmore, D. (Eds.), The Biology of Marsupials. Macmillan Publishers, Melbourne, pp. 273-286. 
Pollock, K.H., 1982. A capture-recapture design robust to unequal probability of capture. J. Wildl. Manag. 46, 752-757.

Robertshaw, J.D., Harden, R., 1989. Predation on Macropodoidea: a review. In: Grigg, G., Jarman, P., Hume, I. (Eds.), Kangaroos, Wallabies and Rat-kangaroos; Vol. 2. Surrey Beatty \& Sons Pty Ltd, Sydney, Australia, pp. 735-753.

Robertshaw, J.D., Harden, R.H., 1986. The ecology of the dingo in north-eastern New South Wales. IV. Prey selection by dingoes, and its effect on the major prey species, the swamp wallaby, Wallabia bicolor (Desmarest). Wildl. Res. 13, 141-163.

Seber, G.A.F., 1982. The Estimation of Animal Abundance and Related Parameters, second ed. Charles Griffin \& Co. Ltd, London, UK.

Sharman, G.B., 1955a. Studies on marsupial reproduction. II. The oestrous cycle of Setonix brachyurus. Aust. J. Zool. 3, 44-55.

Sharman, G.B., 1955b. Studies on marsupial reproduction. III. Normal and delayed pregnancy in Setonix brachyurus. Aust. J. Zool. 3, 56-70.

Sharman, G.B., Maynes, G.M., 1995. Rock-wallabies. In: Strahan, R. (Ed.), Mammals of Australia. Reed Books, Sydney, Australia, pp. 363-364.

Shield, J.W., 1964. A breeding season difference in two populations of the Australian macropod marsupial (Setonix brachyurus). J. Mammal. 45, 616-625.

Shield, J.W., 1968. Reproduction of the quokka, Setonix brachyurus, in captivity. J. Zool. (Lond.) 155, 427-444.

Shield, J.W., Woolley, P., 1961. Age estimation by measurement of pouch young of the quokka (Setonix brachyurus). Aust. J. Zool. 9, 14-23.

Shield, J.W., Woolley, P., 1963. Population aspects of delayed birth in the quokka (Setonix brachyurus). Proc. Zool. Soc. Lond. 141, 783789.

Shortridge, G.C., 1909. An account of the geographical distribution of the marsupials and monetremes of south-west Australia, having special reference to the specimens collected during the Balston Expedition of 1904-1907. Proc. Zool. Soc. Lond. 1909, 803-848.

Sinclair, A.R.E., Pech, R.P., Dickman, C.R., Hik, D., Mahon, P., Newsome, A.E., 1998. Predicting effects of predation on conservation of endangered species. Cons. Biol. 12, 564-575.
Sinclair, E.A., 1998. Morphological variation among populations of the quokka, Setonix brachyurus (Macropodidae: Marsupialia), in Western Australia. Aust. J. Zool. 46, 439-449.

Sinclair, E.A., 2001. Phylogeographic variation in the quokka, Setonix brachyurus (Marsupialia: Macropodidae): implications for conservation. Anim. Cons. 4, 325-333.

Sinclair, E.A., Morris, K.D., 1996. Where have all the quokkas gone? Landscope 11, 49-53.

Sokal, R.R., Rohlf, F.J., 1969. Biometry-The Principles and Practice of Statistics in Biological Research. W.H.Freeman and Co, San Francisco.

Southern, R.L., 1979. The atmosphere. In: O’Brien, B.J. (Ed.), Environment and Science. University of Western Australia, Perth, pp. $183-225$.

Storr, G.M., 1964. The environment of the quokka (Setonix brachyurus) in the Darling Range, Western Australia. J. Roy. Soc. W.A. $47,1-2$.

Thackway, R.M., Cresswell, I.D., 1995. An Interim Biogeographic Regionalisation for Australia: a Framework for Setting Priorities in the National Reserves System Cooperative Program. Australian Nature Conservation Agency, Canberra.

Thomson, P.C., Algar, D., 2000. The uptake of dried meat baits by foxes and investigations of baiting rates in Western Australia. Wildl. Res. 27, 451-456.

Viggers, K.L., Lindenmayer, D.B., Cunningham, R.B., Donnelly, C.F., 1998. Estimating body condition in the mountain brushtail possum, Trichosurus caninus. Wildl. Res. 25, 499-509.

Waring, H., 1956. Marsupial studies in Western Australia. Aust. J. Sci. $18,66-73$.

Waring, H., 1959. Rottnest Island: the Rottnest Biological Station and recent scientific research. Introduction. J. Roy. Soc. W.A. 42, 65-66.

White, G.C., Anderson, D.R., Burnham, K.P., Otis, D.L., 1982. CaptureRecapture and Removal Methods for Sampling Closed Populations. Los Alamos National Laboratory, Los Alamos, New Mexico.

White, G.C., Burnham, K.P., 1999. Program MARK: survival estimation from populations of marked animals. Bird Study 46 (Suppl.), S120-S139.

White, S.R., 1952. The occurrence of the quokka in the south-west. W.A. Nat. 3, 101-103. 